\title{
EFFECT OF CARBON NANOTUBE GRAFTING ONTO CARBON FIBRE ON THE CONDUCTIVITY OF CARBON FIBRE-REINFORCED THERMOPLASTIC LAMINATES
}

\author{
KAZUTO TANAKA, KEN UZUMASA \& TSUTAO KATAYAMA \\ Department of Biomedical Engineering, Doshisha University, Japan
}

\begin{abstract}
Carbon fibre reinforced thermoplastics (CFRTP) can be expected to be used as a structural material for aircraft and automobiles, due to not only mechanical properties such as high specific strength and high specific rigidity, but also for their high recyclability and short moulding time. When lightning hits directly upon an airplane body made from CFRTP, the lightning current does not spread isotropically, which is different from a conductor, causing exterior damage and malfunction of the internal electronic equipment. In recent years, carbon nanotubes (CNTs) were expected to improve the mechanical properties and conductivity of composite materials, due to their excellent mechanical properties, conductivity and high aspect ratio. In this study, we evaluated the effect of CNT grafting onto carbon fibres, on the conductivity of CFRTP. CNT-grafted carbon fibres showed lower resistance values in the $X$ and $Y$ directions compared to carbon fibre alone. Although the resistance of CFRTP laminates using CNT-grafted carbon fibre in the $X$ direction had the same value of CFRTP laminates using control as-received carbon fibre, we found that the resistance of CFRTP laminates using CNT-grafted carbon fibre in both the $Y$ and $Z$ directions had lower values.

Keywords: carbon fibre reinforced thermoplastics, carbon nanotube, carbon nanotube grafted carbon fibre, conductivity, material properties, reinforced thermoplastics, resistance, resistivity.
\end{abstract}

\section{INTRODUCTION}

In recent years, weight reduction of automobiles and aircraft is required, in order to follow regulations on the reduction of carbon dioxide emissions. Carbon fibre reinforced plastics (CFRPs) are expected to be of use for structural parts, due to their mechanical properties that include high stiffness, high strength and low density. Within CFRPs, the carbon fibre reinforced thermoplastics (CFRTP) are especially expected to be applied to mass-produced products in automobiles and aircraft, from the point of view that CFRTP uses thermoplastics which are superior in both recyclability and productivity [1]. Although CFRTP has superior mechanical properties, it should have anisotropy of having not only mechanical properties, but also the right amount of electrical conductivity [2]. When lightning hits an airplane body made from CFRTP directly, the lightning current does not spread isotropically, which is different from a conductor causing exterior damage and malfunction of the internal electronic equipment [3].

Carbon nanotubes (CNTs) are expected to improve the mechanical properties and the conductivity of composite materials, due to their excellent mechanical properties, conductivity and high aspect ratio. One of the issues in using CNT is the difficulty of CNT dispersion within the matrix of CFRTP. In recent years, CNT grafting methods onto carbon fibre have been developed [4]. By using CNT-grafted carbon fibre for reinforcement, the CNTs are automatically dispersed within the matrix after placing the reinforcement.

In this study, we evaluated the effect of CNT grafting onto carbon fibre, on the conductivity of spread carbon fibre and CFRTP laminates. 


\section{MATERIALS AND EXPERIMENTAL PROCEDURES}

\subsection{Materials and CNT grafting}

Spread PAN-based carbon fibres of $24 \mathrm{~K}$ with the width of $23 \mathrm{~mm}$ (Nippon Tokushu Fabric, hereafter referred to as the $\mathrm{CF}$ ) were used in this study. Nickel (Ni) is used as the catalyst for carbon nanotubes in a chemical vapor deposition (CVD) process that carries it onto the surface of the study's carbon fibres: an electrolytic Ni plating method to make Ni-plated carbon fibre (Ni-CF). The plating bath components were Ni sulfate hexahydrate ( $240 \mathrm{~g} / \mathrm{L})$, Ni chloride hexahydrate ( $45 \mathrm{~g} / \mathrm{L})$ and boracic acid (30 g/L). The spread fibres were connected on one end of the electrode and a Ni plate was connected to the other end: they were then dipped in the plating bath, as shown in Fig. 1. The plating time was set for $15 \mathrm{~s}$ and the current was set for $0.3 \mathrm{~A}$.

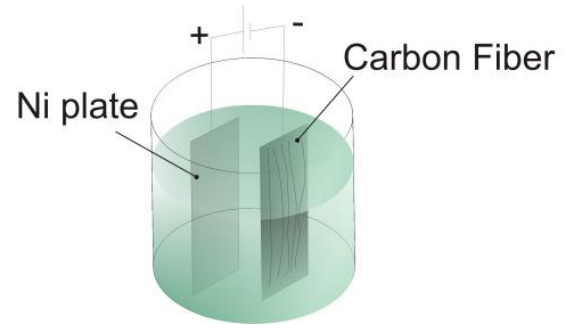

Figure 1: Schematic drawing of Nickel (Ni) plating method.

The CVD system (MPCVD-70, Microphase) shown in Fig. 2 was used for CNT grafting onto Ni-plated spread carbon fibres. The grafting temperature was set at $600^{\circ} \mathrm{C}$, with a flow of ethanol as the carbon source to graft the CNTs, and Argon (Ar) gas was used as the carrier gas. To evaluate the effect of the amount of grafted CNTs on the material's electrical resistance, CNT-grafted carbon fibres were prepared for $10 \mathrm{~min}, 30 \mathrm{~min}$ and $60 \mathrm{~min}$. In this study, these CNT-grafted carbon fibres are referred to as $\mathrm{CNT}_{10}-\mathrm{CF}, \mathrm{CNT}_{30}-\mathrm{CF}$ and $\mathrm{CNT}_{60}$ $\mathrm{CF}$, respectively.

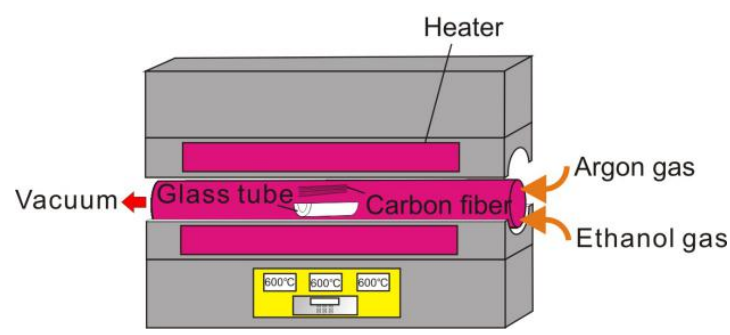

Figure 2: Schematic drawing of the chemical vapor deposition apparatus.

The morphology of the surface and a cross-section of spread carbon fibres were examined by scanning electron microscope (SEM: JSM-6390LT, JEOL) and field emission scanning electron microscope (FE-SEM: JSM-7500FD, JEOL). By using the fibre length and the 
binary image of the SEM image of CNT-CF, we calculated the apparent outer diameter of CNT-CF.

\subsection{Moulding of CFRTP laminate}

In order to clarify the effect of CNT on electrical resistance, we used the $\mathrm{CF}, \mathrm{CNT}_{10}-\mathrm{CF}$, $\mathrm{CNT}_{30}$-CF and $\mathrm{CNT}_{60}-\mathrm{CF}$ for the reinforcement of CFRTP. Non-woven fabric $\left(50 \mathrm{~g} / \mathrm{m}^{2}\right.$, Prototype, Kuraray) manufactured from polyamide 6 (1015B, Ube Industries) was used for the matrix of CFRTP. CFRTP $\left(\left[0^{\circ}\right]_{24}\right.$ with the volume fraction $\left(V_{f}\right)$ of $\left.45 \%\right)$ was moulded by using a stripe-shaped mould, attached to a universal precision testing machine (Autograph, AG-250 kN, Shimadzu), as shown in Fig. 3. The moulding conditions were: $250^{\circ} \mathrm{C}$ for moulding temperature, $3 \mathrm{MPa}$ for moulding pressure and $600 \mathrm{~s}$ for the press holding time. Hereafter, CFRTP moulded by using $\mathrm{CF}, \mathrm{CNT}_{10}-\mathrm{CF}, \mathrm{CNT}_{30}-\mathrm{CF}$ and $\mathrm{CNT}_{60} \mathrm{CF}$ as the reinforcing fibre are referred to as CFRTP, $\mathrm{CNT}_{10}$-CFRTP, $\mathrm{CNT}_{30}$-CFRTP and $\mathrm{CNT}_{60^{-}}$ CFRTP, respectively. The cross sections of these laminates were polished using a cross section polisher (CP, SM-09010, JEOL Ltd.) at a voltage of $5.2 \mathrm{kV}$ for a polishing time of $102 \mathrm{~h}$ and observed by using FE-SEM (SU8020, Hitachi High-Technologies Corporation).

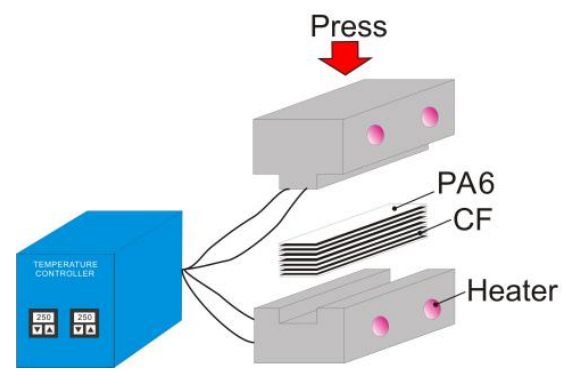

Figure 3: Mould of laminated plate.

\subsection{Resistance measurement of spread carbon fibres}

The electric resistance value of each spread carbon fibre in the fibre longitudinal direction $(X$ direction) and transverse direction ( $Y$ direction) was measured by the direct current (DC) milli-ohm meter (GOM-802, GW Instek), as shown in Fig. 4. The spread carbon fibres are glued together at both ends with electroconductive resin material (Fujikura Kasei Company, D-550).

\subsection{Resistance measurement of CFRTP}

We measured the electric resistance value of CFRTP samples cut out from moulded CFRTP laminates with a digital multimeter (HIOKI, DT4282), as shown in Fig. 5. The measured surfaces were coated by electroconductive resin material. As shown in Fig. 6, we measured the electric resistance values in the fibres' longitudinal $(X)$ direction, transverse $(Y)$ direction, and for thickness $(Z)$. Each volume resistivity was calculated by using eqn (1).

$$
\rho=\frac{R A}{l} .
$$




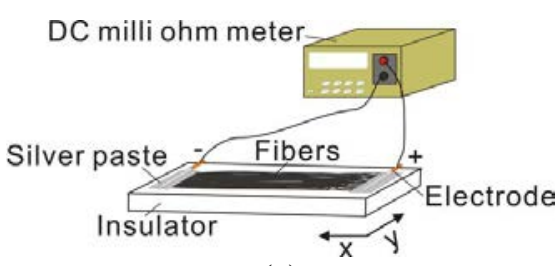

(a)

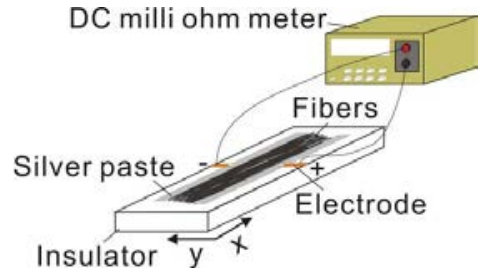

(b)

Figure 4: Schematic drawing of resistance measurement of spread carbon fibres. (a) $X$ axis direction; (b) $Y$ axis direction.

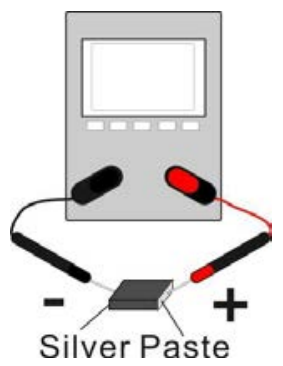

Figure 5: Schematic drawing of resistance measurement of CFRTP.

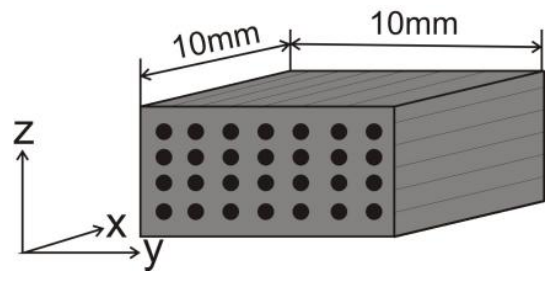

Figure 6: Sample dimension and direction.

\section{RESULTS AND DISCUSSION}

\subsection{SEM observation of carbon fibre surface and cross section}

Fig. 7 shows the surface of (a) $\mathrm{CF}$, (b) Ni-CF, (c) $\mathrm{CNT}_{10^{-}} \mathrm{CF}$, (d) $\mathrm{CNT}_{30^{-}} \mathrm{CF}$ and (e) $\mathrm{CNT}_{60^{-}}$ CF; as observed by SEM. On the Ni-CF surface, the Ni particles are plated onto the carbon fibre surface [5]. On the surface of $\mathrm{CNT}_{10}-\mathrm{CF}, \mathrm{CNT}_{30}-\mathrm{CF}$ and $\mathrm{CNT}_{60}-\mathrm{CF}$, the CNTs are grafted and longer CNTs are observed when the grafting duration is longer. A cross-section of each carbon fibre is show in Fig. 8. CNTs are grafted onto the carbon fibre surface and the CNTs grafted on the neighbouring carbon fibres are connected with each other. The CNT-CF with a longer grafting duration has more connected CNTs. The apparent outer diameter of each carbon fibre is shown in Fig. 9. The CNT-CF with longer grafting duration has larger apparent outer diameters. 


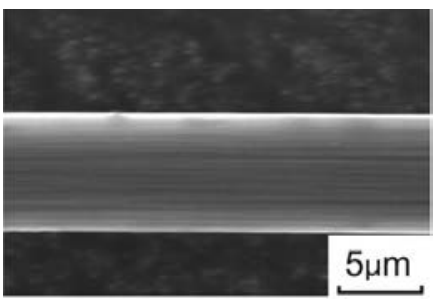

(a)

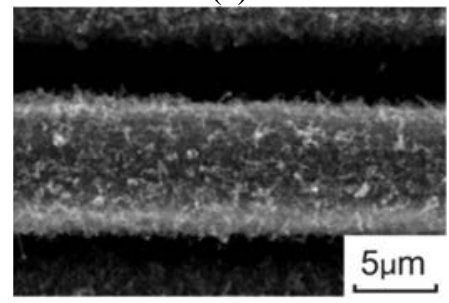

(c)

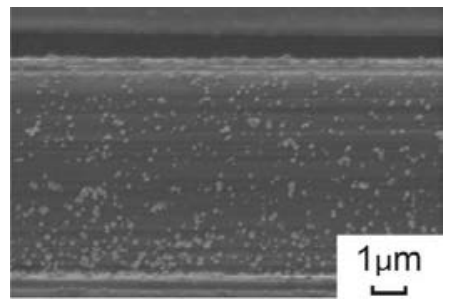

(b)

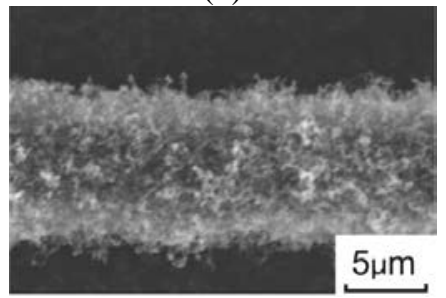

(d)

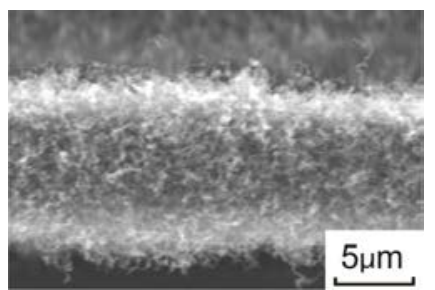

(e)

Figure 7: $\quad$ SEM images of each type of CF. (a) Control CF; (b) Ni-CF; (c) CNT $10-\mathrm{CF}$; (d) $\mathrm{CNT}_{30}-\mathrm{CF}$; and (e) $\mathrm{CNT}_{60}-\mathrm{CF}$. (c)-(e) are our samples, grafted for the different experimental times.

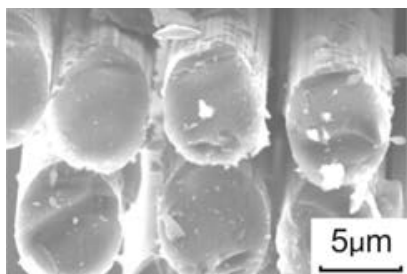

(a)

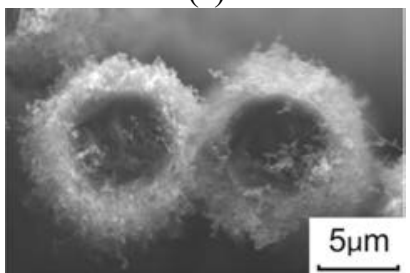

(c)

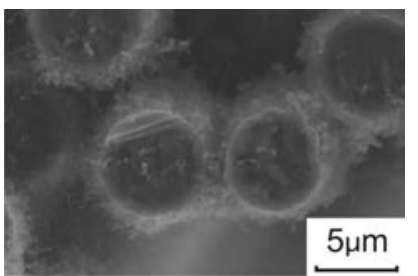

(b)

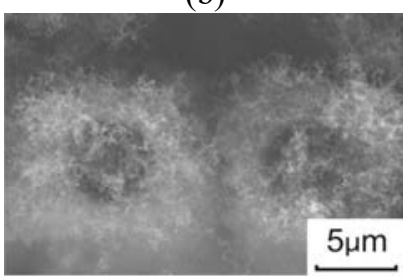

(d)

Figure 8: Cross-sections of the experimental CFs. (a) Control CF; (b) $\mathrm{CNT}_{10}-\mathrm{CF}$; (c) $\mathrm{CNT}_{30}$-CF; and (d) $\mathrm{CNT}_{60}$-CF. 10 to 60 -minute samples. 


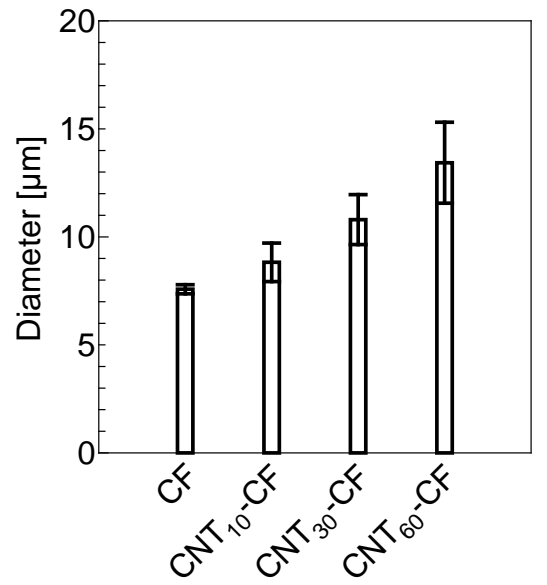

Figure 9: Diameter of CFs by grafting duration.

\subsection{SEM observation of cross-section of CFRTP}

The cross-sections of CFRTP, $\mathrm{CNF}_{10}$-CFRTP, $\mathrm{CNF}_{30}$-CFRTP and $\mathrm{CNF}_{60}$-CFRTP, which were polished using a cross-section polisher, are shown in Fig. 10. In all laminates, resin was impregnated in between the carbon fibres and the CNTs: no void was observed by the resolution with FE-SEM.

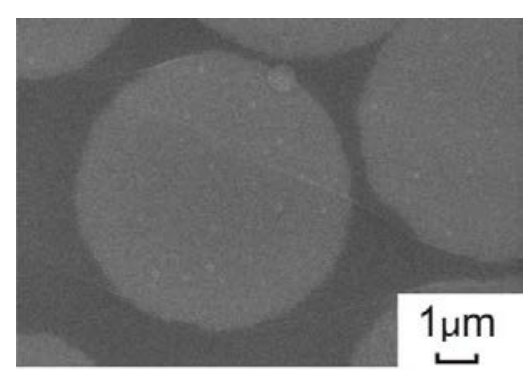

(a)

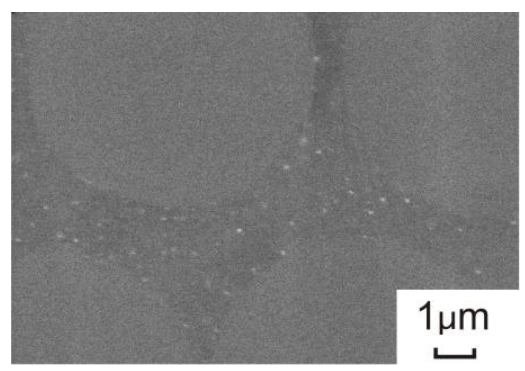

(c)

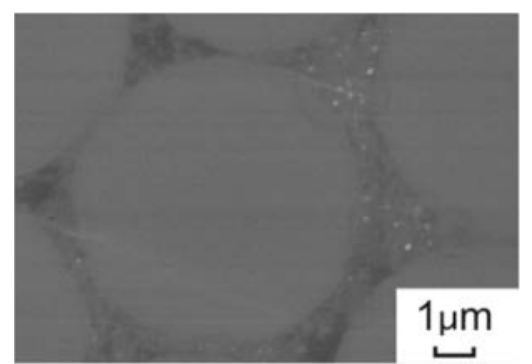

(b)

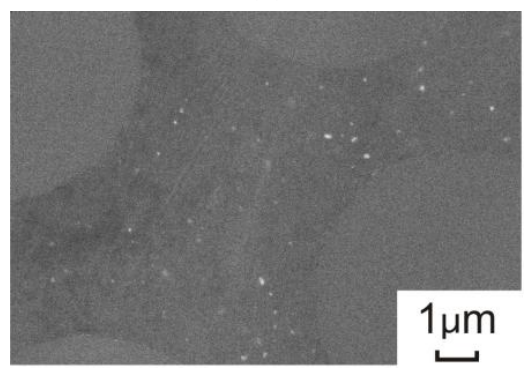

(d)

Figure 10: A cross section of the CFRTPs. (a) Control CFRTP; (b) $\mathrm{CNT}_{10}$-CFRTP; (c) $\mathrm{CNT}_{30}$-CFRTP; and (d) $\mathrm{CNT}_{60}$-CFRTP. 
Fig. 11 shows the carbon-emphasized FE-SEM images. CNTs grafted onto neighbouring carbon fibres are connected with each other. The white particles in Fig. 11(a) are plated Ni, which exists on both the carbon fibre surface and the tip of the CNTs, as was shown in our previous study [6].

Fig. 12 shows the cross-section in between the $0^{\circ}$ layers. A resin rich layer was observed between the $0^{\circ}$ layers.

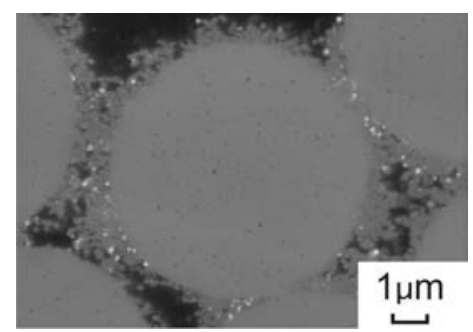

(a)

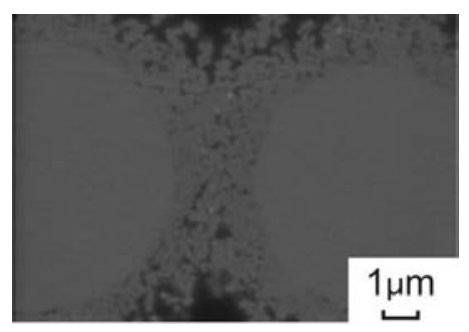

(b)

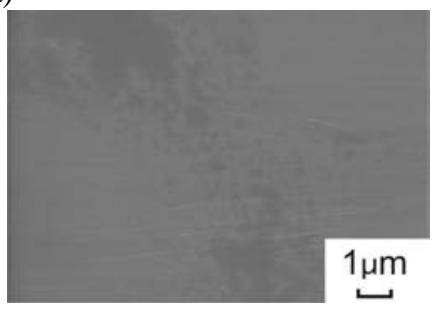

(c)

Figure 11: The cross-sections of experimental CNT-CFRTPs. (a) $\mathrm{CNT}_{10}$-CFRTP; (b) $\mathrm{CNT}_{30}$-CFRTP; and (c) $\mathrm{CNT}_{60}$-CFRTP.
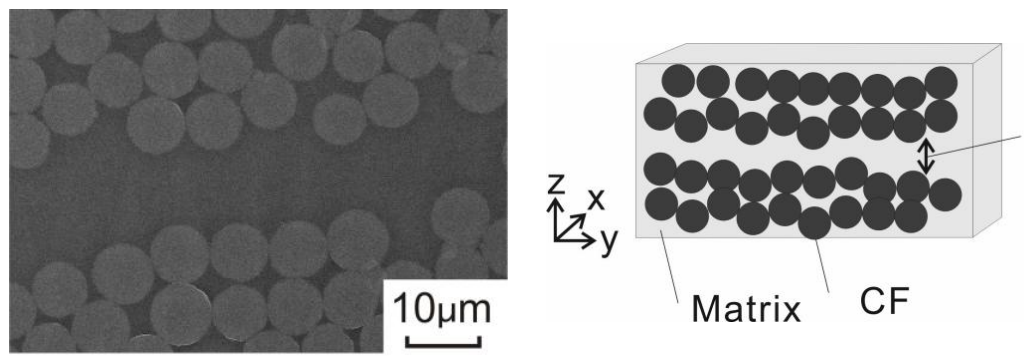

Resin rich layer

Figure 12: Resin-rich layer in between $0^{\circ}$ layers.

\subsection{Electrical resistance of spread carbon fibres}

Fig. 13 shows the electric resistance value of each spread carbon fibre in the fibres' longitudinal direction ( $X$ direction) and transverse direction ( $Y$ direction). We found that the electric resistance value in the $X$ direction of $\mathrm{CNT}_{10}-\mathrm{CF}, \mathrm{CNT}_{30}-\mathrm{CF}$ and $\mathrm{CNT}_{60}-\mathrm{CF}$ is lower than that of CF. There is no big difference in the electric resistance value in the $X$ direction 
for $\mathrm{CNT}_{10}-\mathrm{CF}, \mathrm{CNT}_{30}-\mathrm{CF}$ and $\mathrm{CNT}_{60}-\mathrm{CF}$. In contrast, the electric resistance value in the $Y$ direction of $\mathrm{CNT}_{10}-\mathrm{CF}, \mathrm{CNT}_{30}-\mathrm{CF}$ and $\mathrm{CNT}_{60}-\mathrm{CF}$ is lower than that of $\mathrm{CF}$.

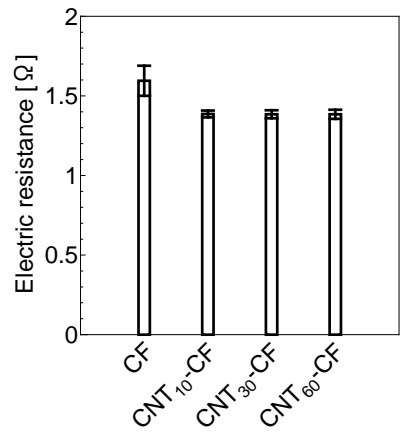

(a)

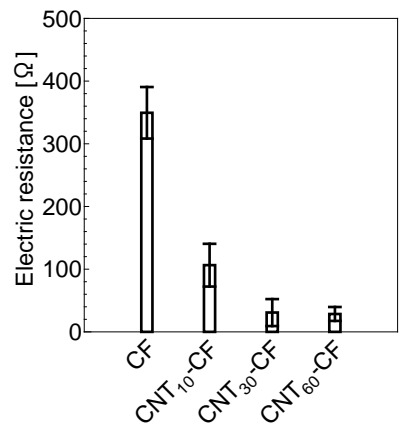

(b)

Figure 13: Electrical resistance in the $X$ and $Y$ direction of spread carbon fibre. (a) Spread carbon fibre measured in the $X$ direction; and (b) Spread carbon fibre measured for resistance in the $Y$ direction.

The CNT-CF with longer grafting durations tend to show a lower electric resistance value. As shown in Fig. 11, the connected CNTs on neighbouring carbon fibres are considered to contribute towards the making of conductive paths and in giving lower electrical resistance values [7], [8].

\subsection{Volume resistivity of CFRTP}

The volume resistivities of CFRTP are shown in Fig. 14. The volume resistivities of CFRTP, $\mathrm{CNT}_{10}$-CFRTP, $\mathrm{CNT}_{30}$-CFRTP and $\mathrm{CNT}_{60}$-CFRTP in the $X$ direction basically have no significant differences. On the contrary, we found that the volume resistivities in the $Y$ and $Z$ directions of $\mathrm{CNT}_{10}$-CFRTP, $\mathrm{CNT}_{30}$-CFRTP and $\mathrm{CNT}_{60}$-CFRTP were lower than those of our control CFRTP. The CFRTP that used CNT-CF with a longer grafting duration, tended to show lower volume resistivity.

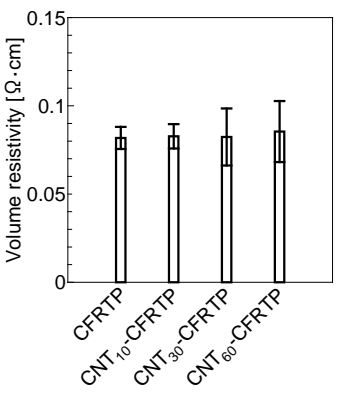

(a)

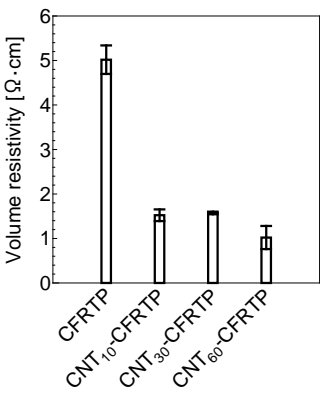

(b)

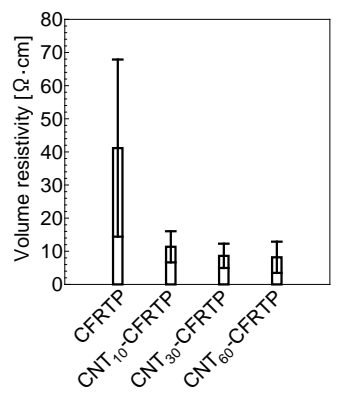

(c)

Figure 14: Resistivity of CFRTP. (a) Control and sample measurements in the $X$ direction; (b) Measurements in the $Y$ direction; and (c) Measurements in the $Z$ direction. 
Fig. 15 shows the summarized graph of volume resistivity in the $X$ and $Y$ directions. The difference of volume resistivity in the $X$ and $Y$ directions becomes smaller with the larger diameter of carbon fibre by CNT grafting, as shown in Fig. 9. Grafting CNTs onto carbon fibres can contribute to the reduction of the anisotropy of resistivity of the CFRTP laminates.

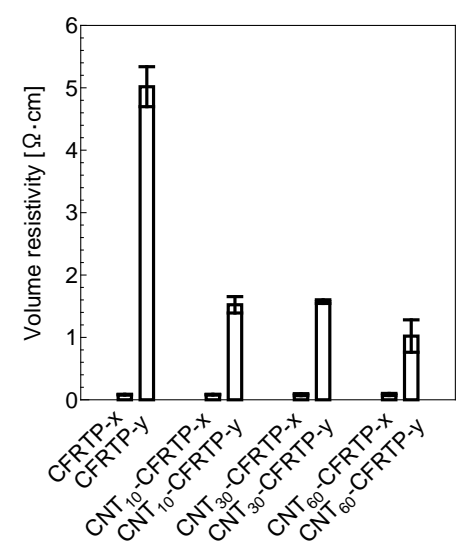

Figure 15: Volume resistivity in the $X$ and $Y$ direction.

\section{CONCLUSIONS}

The effect of CNT grafting onto carbon fibres on the conductivity of the spread carbon fibres and CFRTP was evaluated. The investigation yielded the following conclusions:

1. The CNT-grafted carbon fibre shows lower resistance values in the $X$ and $Y$ directions, compared to the control as-received carbon fibre.

2. Although the resistance of CFRTP laminates using CNT-grafted carbon fibre in the $X$ direction has the same value of control CFRTP laminates using as-received carbon fibre, the resistance of CFRTP laminates using CNT-grafted carbon fibre in the $Y$ and $Z$ directions have lower values. Thus, grafting CNTs onto carbon fibre can contribute to reducing the anisotropy of resistivity of CFRTP laminates.

\section{ACKNOWLEDGEMENTS}

This work was partially supported by KAKENHI (Japan Society for the Promotion of Science), Grant-in-Aid for Scientific Research (B) number 26289011; and also, a research project on "Research and Development Centre for Advanced Composite Materials" through Doshisha University and MEXT (Ministry of Education, Culture, Sports, Science and Technology, Japan), a Supported Program for the Strategic Research Foundation at Private Universities, provided for 2013-2017, project S1311036.

\section{REFERENCES}

[1] Marsh, G., Reinforced thermoplastics: The next wave? Reinforced Plastics, 58(4), pp. 24-28, 2014.

[2] Todoroki, A., Suzuki, H., Kobayashi, H., Nakamura, H. \& Shimamura, Y., Evaluation of orthotropic electrical resistance for delamination detection of CFRP by electrical potential method. Transactions of the JSME, 64(622), pp. 1654-1659, 1998. 
[3] Yamamoto, K., New lightning protection technologies for airplanes using composite materials. IEEJ Transactions on Power and Energy, 133(9), pp. 690-693, 2013.

[4] Tanaka, K., Okumura, Y., Katayama, T. \& Morita, Y., Effect of carbon nanotubes deposition form on carbon fiber and polyamide resin interfacial strength. Journal of the Society of Materials Science, 65(8), pp. 586-591, 2016.

[5] Tanaka, K., Uzumasa, K. \& Katayama, T., Effect of CNT grafting on carbon fibers on impact properties of CFRTP laminate. Key Engineering Materials, 774, pp. 410-415, 2018.

[6] Tanaka, K., Nishikawa, T., Aoto, K. \& Katayama, T., Effect of carbon nanotube deposition time to the surface of carbon fibres on flexural strength of resistance welded carbon fibre reinforced thermoplastics using carbon nanotube grafted carbon fibre as heating element. Journal of Composites Science, 3(1), p. 9, 2019.

[7] Takase, H., Mikata, Y., Matsuda, S. \& Murakami, A., Dispersion of carbon nanotubes in a polymer matrix by a twin-screw extruder. Seikei-Kakou, 14(2), pp. 126-131, 2002.

[8] Kumagai, T., Suzuki, W., Yamada, E., Noguchi, T., Iinou, S. \& Endo, M., Properties of multiwall carbon nanotubes/polystyrene-block-polybutadiene-block-polystyrene composites. Journal of Japan Rubber Association, 83(8), pp. 258-263, 2010. 